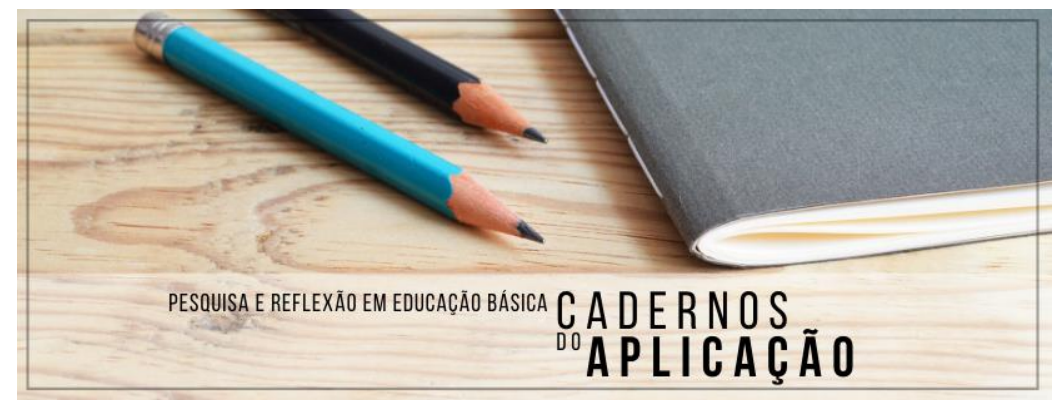

Cadernos do Aplicação

https://seer.ufrgs.br/CadernosdoAplicacao

Publicação Ahead of Print

ISSN 2595-4377 (online)

Porto Alegre | jul-dez. 2021 | v.34 | n.2

\title{
Práticas pedagógicas na escola inclusiva: entre adaptar e reinventar
}

\author{
Marilia Salles Bastos ${ }^{1}$ \\ Eliana da Costa Pereira de Menezes ${ }^{2}$
}

\begin{abstract}
Resumo: Esta pesquisa surge de inquietações com as políticas da educação especial, que vêm desafiando o contexto escolar. Em especial, nesta investigação, tratamos das concepções e práticas pedagógicas que estão sendo construídas em meio às mudanças na educação. Nosso objetivo geral é compreender as concepções que compõem as práticas pedagógicas consideradas "práticas de adaptação curricular" desenvolvidas no contexto da educação inclusiva. A metodologia caracteriza-se como pesquisa qualitativa de abordagem narrativa sociocultural; para a coleta dos dados, utilizamos a entrevista narrativa semiestruturada. As colaboradoras foram quatro professoras de uma escola da rede municipal de ensino de Santa Maria (RS). Nossa escrita fundamenta-se, além dos documentos legais, nos estudos de Bolzan (2002), Beyer (2008), Michels et al. (2010), Carvalho (2013), Libâneo (2013) e Ball et al. (2016), entre outros. Com esta investigação, entendemos que no grupo de professoras há uma "sintonia" profissional, na busca de fazer e ser o mais correspondente possível para/no contexto da educação inclusiva. Assim, a escola ora configura as práticas a partir da vontade de adaptar e reafirmar o já instituído, ora anuncia uma vontade de ressignificação, propondo não um currículo adaptado para alguns, mas a sua reinvenção visando ao todo.
\end{abstract}

Palavras-chave: Inclusão. Práticas pedagógicas. Adaptação curricular. Reinvenção.

\section{Pedagogic practices in the inclusive school: between adapting and reinventing}

\begin{abstract}
This research has emerged from concerns about Special Education policies, which have challenged the school context. Particularly, in this investigation, we address pedagogical conceptions and practices designed amidst changes in education. Our general objective is to understand the conceptions that have underpinned pedagogical practices regarded as "curriculum adaptation practices" performed in the context of inclusive education. The methodology is characterized as qualitative research with a social-cultural narrative approach; for data collection, we used the semistructured narrative interview. The collaborators were four teachers of a school belonging to the education network of the city of Santa Maria (RS). Besides legal documents, we have grounded our
\end{abstract}

\footnotetext{
${ }^{1}$ Especialista em Gestão Escolar (IFFar - Campus Júlio de Castilhos/RS), Licenciada em Pedagogia (UFSM), Licenciada em Educação Especial (UFSM). Professora de Atendimento Educacional Especializado na rede municipal de ensino no município de Santo Ângelo/RS. E-mail: mariliasb.18@gmail.com ORCID iD: https://orcid.org/0000-0002-6538-2797

${ }^{2}$ Doutora em Educação (UNISINOS), Mestre em Educação (UFSM), Licenciada em Educação Especial (UFSM). Professora Associada do Departamento de Educação Especial da UFSM. E-mail: eliana.menezes@ufsm.br ORCID iD: https://orcid.org/0000-0002-5908-0039
} 


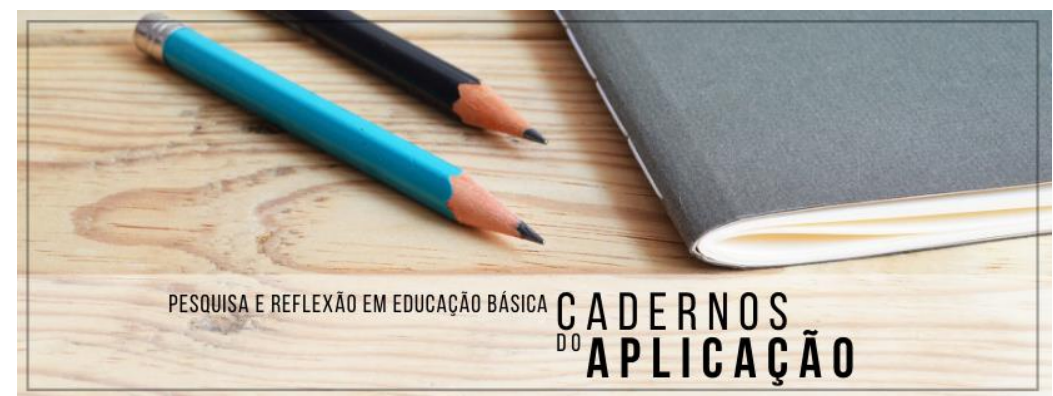

Cadernos do Aplicação

https://seer.ufrgs.br/CadernosdoAplicacao

Publicação Ahead of Print

ISSN 2595-4377 (online)

Porto Alegre | jul-dez. 2021 | v.34 | n.2

writing on studies by Bolzan (2002), Beyer (2008), Michels et al. (2010), Carvalho (2013), Libâneo (2013) and Ball et al. (2016), among others. With this investigation, we have noticed a kind of professional "accordance" in the group of teachers in their attempt to act and be as fitted as possible for/in the context of inclusive education. Hence, sometimes the school is willing to organize practices in order to adapt and reassert what has been settled, sometimes it is willing to re-signify them, not by proposing a curriculum adapted to some, but rather its reinvention intended for all.

Keywords: Inclusion. Pedagogical practices. Curriculum adaptation. Reinvention.

\section{Prácticas pedagógicas en la escuela inclusiva: entre adaptar y reinventar}

Resumen: Esta investigación surge de inquietudes con las políticas de la Educación Especial que vienen desafiando el contexto escolar. En particular, en esta investigación nos ocupamos de las concepciones y prácticas pedagógicas que se están construyendo en medio de los cambios en la educación. Nuestro objetivo general fue comprender las concepciones que componen las prácticas pedagógicas consideradas "prácticas de adaptación curricular" desarrolladas en el contexto de la educación inclusiva. La metodología se caracteriza como investigación cualitativa de abordaje narrativa sociocultural; para la recolección de datos, utilizamos la entrevista narrativa semiestructurada. Las colaboradoras fueron cuatro profesoras de una escuela de la red municipal de enseñanza de Santa Maria (RS). Nuestra redacción se basa, además de documentos legales, en los estudios de Bolzan (2002), Beyer (2008), Michels et al. (2010), Carvalho (2013), Libâneo (2013) y Ball et al. (2016), entre otros. Con esta investigación, entendemos que en el grupo de profesoras existe una "sintonía" profesional, en la búsqueda de hacer y ser lo más correspondiente posible paral en el contexto de la educación inclusiva. Así, la escuela a veces configura prácticas basadas en el deseo de adecuar y reafirmar lo que ya está instituido, a veces anuncia un deseo de resignificación, proponiendo no un plan de estudios adaptado para algunos, sino su reinvención apuntando a la totalidad.

Palabras clave: Inclusión. Prácticas pedagógicas. Adaptación curricular. Reinvención.

\section{Inclusão, experiências escolares e a proposição da pesquisa}

As problematizações aqui apresentadas acerca da educação inclusiva constituem fragmentos de uma pesquisa cujo objetivo é compreender as concepções que compõem as práticas pedagógicas consideradas "práticas de adaptação curricular" desenvolvidas no contexto da educação inclusiva. $\mathrm{O}$ estudo foi realizado a partir de uma pesquisa qualitativa de abordagem narrativa sociocultural ${ }^{3}$, a qual implica a compreensão do processo de

\footnotetext{
${ }^{3}$ A abordagem narrativa sociocultural vem sendo estudada e construída pelo Grupo de Pesquisa GPFOPE, sob coordenação da professora Dra. Doris Pires Vargas Bolzan, no Centro de Educação da UFSM. Essa abordagem
} 
transformação dos sujeitos, levando em conta as suas experiências e vivências, seu contexto, seu ambiente e sua história (BOLZAN, 2002). Assim, como materialidade analítica, foram utilizadas entrevistas narrativas produzidas com quatro professoras da educação básica - três professoras de anos iniciais do ensino fundamental e uma professora da educação especial - que atuavam em uma escola de ensino fundamental no município de Santa Maria (RS). As professoras serão identificadas com pseudônimos: Cecília (professora do $1^{\circ}$ ano), Antônia (professora do $3^{\circ}$ ano), Renata (professora do $4^{\circ}$ ano) e Francisca (professora da educação especial $)^{4}$.

$\mathrm{Na}$ abordagem sociocultural, compreende-se que a entrevista narrativa semiestruturada, mais do que uma simples troca de perguntas e respostas, acontece a partir de uma conversa, com respostas pautadas no diálogo e na construção de ideias (ROSSETO et al., 2014). Logo, por meio da narrativa, as pessoas lembram sua trajetória pessoal, social e profissional e, a partir de suas experiências e vivências, encontram possíveis explicações para os acontecimentos (JOVCHELOVITCH e BAUER 2002). Desse modo, as vozes levam-nos a compreender o sujeito, o que se "[...] está vivendo em um contínuo contexto experiencial, social e cultural, ao mesmo tempo que contamos nossas histórias, refletimos sobre nossas vivências, explicitando a todos nossos pensamentos, através das nossas vozes" (BOLZAN, 2002, p. 72). Por isso, ao construirmos uma analítica, interpretamos e explicamos as narrativas, buscando considerar a bagagem histórica que constitui cada sujeito.

O caminho percorrido na pesquisa qualitativa de abordagem narrativa sociocultural acontece por meio da colaboração e confiança entre o pesquisador e os sujeitos participantes da investigação, os quais narram suas trajetórias pessoais e profissionais, dando sentido e significado às experiências e vivências produzidas em um determinado contexto. Ao mesmo tempo em que as histórias são narradas, acontece a reflexão e compreensão dos acontecimentos em um tempo e espaço, o que posteriormente, possibilita um processo de transformação.

Delimitando o percurso investigativo que dá condições para a proposição deste artigo, nossa intenção previa uma discussão específica relativa às concepções de professoras que têm

\footnotetext{
fundamenta-se nos estudos de Vygotski (1995, 2003, 2007), Bakhtin (1986), Connelly e Clandinin (1995), Freitas (1994, 1996, 1998), Goldemberg (2003) e Bolzan (2002, 2006, 2008, 2010, 2013, 2014, 2015, 2016).

${ }^{4}$ Por atenção aos princípios éticos na realização de pesquisas em Ciências Humanas, as entrevistas foram feitas após assinatura do Termo de Consentimento Livre e Esclarecido pelas pesquisadoras e pelas professoras.
} 
alunos em processo de inclusão escolar sobre adaptações curriculares, procurando compreender como organizam práticas desenvolvidas com esses alunos para que eles tenham acesso ao currículo escolar. Tal intencionalidade resulta de experiências e inquietações que constituem nossas vivências docentes em espaços educacionais, diante das políticas de inclusão escolar que têm orientado mudanças importantes na configuração da escola comum ${ }^{5}$ e da área da educação especial no país desde a década final do século XX.

Com a emergência de tais políticas, um dos conceitos que passam a circular nos espaços escolares é o de "adaptações curriculares"6. Com ele, questionamentos vêm povoar nossas inquietações: “Como fazer adaptações curriculares?”; “O que são adaptações?”; Como o professor as significa?". Assumindo tais questionamentos como foco da pesquisa desenvolvida, estruturamos o percurso investigativo e dirigimo-nos a uma escola da rede municipal de ensino de Santa Maria (RS) em busca de respostas específicas sobre o conceito ora em tensionamento.

Inicialmente construímos um roteiro com perguntas abordando o entendimento das professoras sobre a inclusão; o que elas consideravam importante que os estudantes aprendessem; como o planejamento era construído - estratégias e recursos utilizados para atender as necessidades dos estudantes; como, e se acontecia, o diálogo entre a professora da sala de aula e a professora da educação especial; o que elas entendiam sobre adaptações curriculares e se elas faziam adaptações. Para a professora da educação especial preparamos um roteiro específico, discorrendo sobre o seu entendimento em relação à inclusão; organização da escola para atender as necessidades dos alunos público-alvo; diálogo entre a professora da educação especial e as professoras de sala de aula e as adaptações curriculares.

Durante as entrevistas, fez-se necessária a reorganização das intencionalidades do próprio estudo, uma vez que as narrativas das professoras nos mostraram que, para pensarmos sobre adaptações curriculares, seria preciso também compreender concepções de inclusão, currículo, prática pedagógica, atuação da educação especial na escola, entre outras, o que produziu como efeito a ampliação do olhar direcionado para o que era narrado. Como são planejadas e desenvolvidas as práticas pedagógicas e as ações que envolvem os estudantes na

\footnotetext{
${ }^{5}$ Entende-se como escola comum aquela que atende a todos os públicos, neste caso, sujeitos com e sem deficiência, ou seja, ela não é escola de educação especial, a qual atende somente o público-alvo da educação especial.

${ }^{6}$ Tal conceito posteriormente passou por transformações, tendo sido substituído pelo de flexibilização curricular, como traremos em nossa escrita.
} 


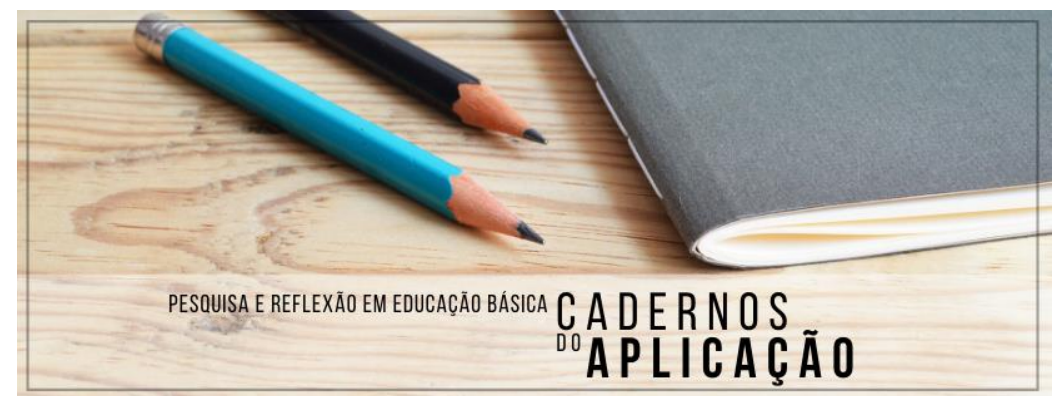

Cadernos do Aplicação

https://seer.ufrgs.br/CadernosdoAplicacao

Publicação Ahead of Print

ISSN 2595-4377 (online)

Porto Alegre | jul-dez. 2021 | v.34 | n.2

escola? Quem as planeja? O currículo que se constrói em uma instituição organizada na perspectiva da educação inclusiva propõe-se dinâmico e atento a todos os estudantes, ou são os estudantes que precisam adaptar-se ao currículo da escola? Que relações são estabelecidas entre o professor de turma e o professor de educação especial? Tais questões passaram, então, a direcionar o percurso investigativo e também as discussões desenvolvidas na sequência do texto.

\section{Inclusão escolar: práticas curriculares, adaptações e reinvenções pedagógicas}

Ao tomarmos a noção de "adaptações curriculares" como central no estudo proposto, assumimos uma forma de significá-las que perpassa a adoção de estratégias, recursos e metodologias que o professor busca para que o estudante público-alvo da educação especial possa participar, construir conhecimento e desenvolver-se no contexto escolar. Esse termo foi abordado até meados do ano de 2008, tendo sido substituído por "flexibilização do currículo", conforme anunciam documentos legais e diretrizes normativas em educação, como as Diretrizes Nacionais para a Educação Especial na Educação Básica (2001) e Práticas em Educação Especial e Inclusiva (2008).

Podemos apontar que, no Brasil, foi durante a década final do século XX e a década inicial do século XXI que documentos significativos relativos à inclusão escolar foram publicados. Tais documentos instituem a obrigatoriedade da escola inclusiva, indicando a necessidade de garantia de matrícula de alunos público-alvo da educação especial nas escolas comuns. Essa garantia de matrícula pressupunha também a proposição de mudanças nas práticas escolares para que fosse possível atender às especificidades de todos os alunos. A Lei de Diretrizes e Bases da Educação Nacional n. ${ }^{\circ}$ 9.394/96 (1996) não cita a expressão "adaptações curriculares", mas indica que o sistema de ensino deve assegurar técnicas, métodos, recursos educativos, currículos e organizações específicas para atender às necessidades dos estudantes com necessidades especiais. É nas Diretrizes Nacionais para a Educação Especial na Educação Básica, Resolução n. ${ }^{\circ}$ 2, de 11 de setembro de 2001, que os termos "flexibilização" e "adaptação curricular" aparecem pela primeira vez. 


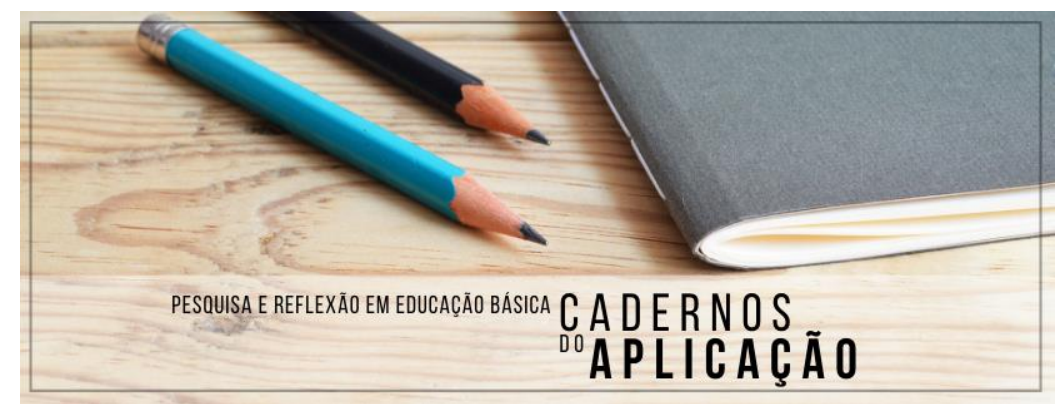

Cadernos do Aplicação

https://seer.ufrgs.br/CadernosdoAplicacao

Publicação Ahead of Print

ISSN 2595-4377 (online)

Porto Alegre | jul-dez. 2021 | v.34 | n.2

$\mathrm{Na}$ organização das classes comuns, faz-se necessário prover: [...] c) flexibilizações e adaptações curriculares, que considerem o significado prático e instrumental dos conteúdos básicos, metodologias de ensino e recursos didáticos diferenciados e processos de avaliação adequados ao desenvolvimento dos alunos que apresentam necessidades educacionais especiais, em consonância com o projeto pedagógico da escola, respeitada a frequência obrigatória [...]. (BRASIL, 2001, p. 47).

A partir desse documento, deu-se a publicação da série Saberes e Práticas da Inclusão Estratégias para a educação de alunos com necessidades educacionais especiais (2003), que indica a necessidade de proposição de adequações curriculares que pudessem prever pequenos e/ou grandes ajustes. Segundo esse documento,

As adequações curriculares constituem, pois, possibilidades educacionais de atuar frente às dificuldades de aprendizagem dos alunos. Pressupõem que se realize a adequação do currículo regular, quando necessário, para torná-lo apropriado às peculiaridades dos alunos com necessidades especiais. Não um novo currículo, mas um currículo dinâmico, alterável, passível de ampliação, para que atenda realmente a todos os educandos. Nessas circunstâncias, as adequações curriculares implicam a planificação pedagógica e a ações docentes fundamentadas em critérios que definem: o que o aluno deve aprender; como e quando aprender; que formas de organização do ensino são mais eficientes para o processo de aprendizagem; como e quando avaliar o aluno (ARANHA, 2003, p. 34).

Entendemos, então, que a emergência de discursos e políticas inclusivas no país, ao produzir a escola como um espaço de atenção às peculiaridades dos alunos, provoca a necessidade de revisitação dos princípios que sustentam as práticas escolares há séculos. Por que, como e para quem propomos currículos e organizamos a escola na contemporaneidade? Que efeitos produzimos com as práticas que desenvolvemos? Tem sido possível, a partir delas, destinar um olhar singular para cada aluno? É preciso e possível reinventarmo-nos enquanto sujeitos que fazem a escola e assim reinventarmos a escola? É pela aposta na possibilidade de reinvenção da escola e pela defesa de sua necessidade que trazemos Xavier (2008) quando argumenta que

A escola tem, diante de si, o desafio de sua própria recriação, se considerarmos que tudo que a ela se refere constitui-se como invenção. Nesse sentido, são invenções de uma determinada época e a partir de determinados propósitos, portanto passíveis de reinvenção, projetos político-pedagógicos; organizações curriculares; listagem de conteúdos; atividades pedagógicas; divisão disciplinar dos conhecimentos; processos de avaliação traduzidos em provas 
ou exames; organização espaço-temporal - duração do ano letivo, turnos, séries, turmas, enturmação por faixa-etária, horários, ou seja, como afirma Celso Vasconcelos (2007), são invenções todos os rituais escolares (p. 324).

Neste grupo heterogêneo de invenções que historicamente fazem a escola ser como é na atualidade, visualizamos também a padronização das expectativas quanto às aprendizagens dos alunos e a normatização do desenvolvimento dos alunos, o que direciona a maneira como as práticas e os currículos são estruturados. Nesse sentido, na discussão proposta por Xavier (2008), o que nos mobiliza é a sua defesa de que, se inventamos a escola da forma como hoje ela se materializa, também podemos inventá-la de outras formas, afinal, "é necessário e possível produzir processos de instauração de novas práticas para a educação de gerações que vivem e viverão em um mundo diferente daquele para o qual a escola foi criada" (p. 324).

Diante dessa aposta na possibilidade de mudança e reinvenção da escola, entendemos que as políticas inclusivas podem ser pensadas, como já afirmamos aqui, como gatilhos que acionam a necessidade de tensionamento do tradicionalmente instituído. Nesse processo de tensionamento, a proposição de práticas inclusivas pode ser pensada em pelo menos dois pontos.

Um deles indica uma compreensão de inclusão escolar centrada na atuação da educação especial como um adendo à escola. Uma escola que passa a não se perceber mais a mesma, entre outros motivos, porque, diante do currículo comum (que se mantém), propõe adaptações destinadas a alguns alunos e, com isso, produz a aproximação de práticas - do ensino comum e de educação especial - que continuam sendo vistas de modo paralelo. Um segundo ponto, que nos parece significativamente mais potente, indica que a presença da educação especial na escola é significada como um dos elementos importantes na reconfiguração das práticas operadas pelos discursos inclusivos, mas não "o" mais importante. Nessa concepção, visualizase uma aposta na articulação dos planejamentos e das ações pedagógicas, resultando não em um currículo adaptado para alguns, mas sim reinventado para todos.

Considerando essas duas possibilidades analíticas, entendemos ser importante destacar que a Política Nacional de Educação Especial na Perspectiva da Educação Inclusiva - PNEEPEI (2008), indica a educação especial como uma modalidade que perpassa todos os níveis, etapas e modalidades de ensino, desenvolve o Atendimento Educacional Especializado (AEE), oferece serviços e recursos e orienta os estudantes e professores das turmas comuns do ensino regular 


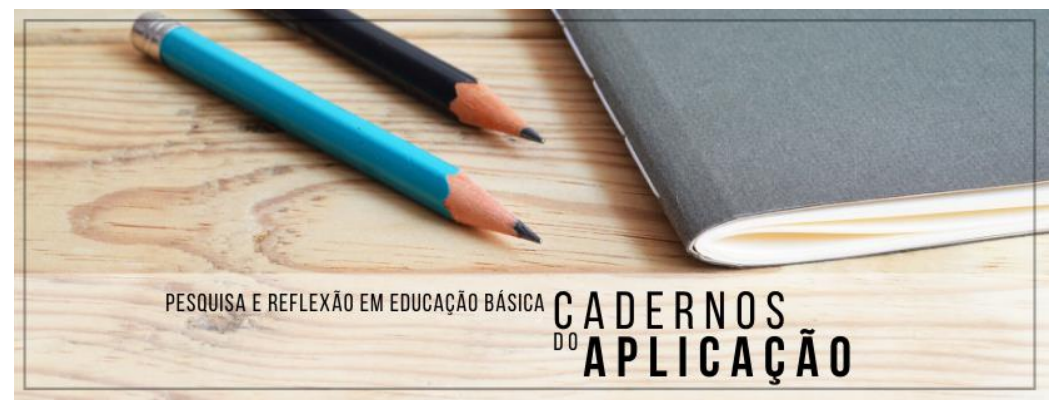

Cadernos do Aplicação https://seer.ufrgs.br/CadernosdoAplicacao

Publicação Ahead of Print

ISSN 2595-4377 (online)

Porto Alegre | jul-dez. 2021 | v.34 | n.2

(BRASIL, 2008). No entanto, é possível propor, como convida Carvalho (2013), uma problematização dos perigos desse olhar sobre a educação especial como uma modalidade de educação. Para a autora, parece ser

[...] mais pertinente entendê-la como processo, pois, na condição de modalidade, faz supor, equivocadamente, um modo diferente de ser, numa abordagem substantiva e que pode alimentar a duplicidade existente: educação regular e Educação Especial, numa visão bipolar geradora de sistemas de atendimento educacional escolar fragmentados (p. 67).

Na perspectiva da educação inclusiva, quando as ações da educação especial passam a constituir a proposta pedagógica da escola em articulação com as demais ações previstas, é possível visualizar uma forma de significação que transpõe a oferta paralela de práticas especializadas. Pode-se entender que, nesse contexto, “[...] a proposta de inclusão é muito mais abrangente e significativa do que o simples fazer parte (de qualquer aluno), sem assegurar e garantir sua ativa participação em todas as atividades [...]” (CARVALHO, 2013, p.111).

Como professoras de educação especial, acompanhamos já há alguns anos os impactos das políticas inclusivas nas escolas comuns, o que nos possibilita avaliar, sem desconsiderar que cada escola se organiza em função de um contexto específico, que há escolas que se desafiam a esse repensar-se diante dos princípios educacionais inclusivos. Isso significa enfrentar uma "realidade pedagógica que ainda não possuem e com a qual ainda não estão familiarizadas" (BEYER In: FREITAS, 2008, p. 86). Nesse sentido, atentas ao contexto singular do presente estudo, procuramos construir uma análise das concepções que compõem as práticas pedagógicas consideradas como "práticas de adaptação curricular”, entendendo que são as concepções que direcionam as práticas o que nos indicará como a escola tem (e se tem) se reinventado.

Ao discutir a organização da escola, Libâneo (2013) destaca quatro aspectos que, para ele, são centrais. O primeiro é a organização da vida escolar, que se refere à organização dos meios de trabalho, proporcionando as condições necessárias para o processo de ensino e de aprendizagem; o segundo aspecto é a organização dos processos de ensino e aprendizagem currículo, organização pedagógico-didática, avaliação, ações de formação continuada, entre outros; a organização das atividades de apoio técnico-administrativo; e, por fim, a organização de atividades que asseguram a relação entre escola e comunidade. Nesse sentido, o autor 


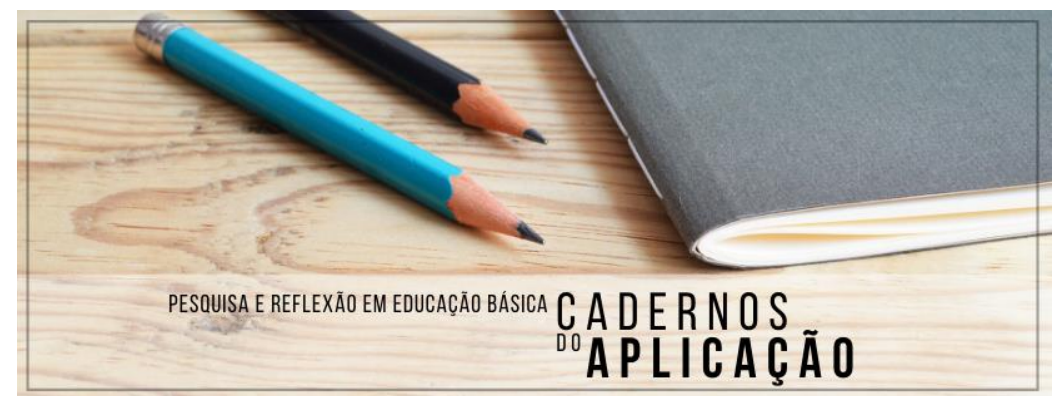

Cadernos do Aplicação https://seer.ufrgs.br/CadernosdoAplicacao

Publicação Ahead of Print

ISSN 2595-4377 (online)

Porto Alegre | jul-dez. 2021 | v.34 | n.2

defende que "a presença ou a falta de organização, expressa em normas, rotinas, atribuições de responsabilidades, interfere na qualidade das atividades de ensino" (p. 169).

Entendemos aqui que falar em organização escolar pressupõe falar em planejamento e que este, por sua vez, pressupõe um caráter processual "[...] de conhecimento e análise da realidade escolar em suas condições concretas, de busca de alternativas para a solução de problemas e de tomada de decisões, possibilitando a revisão dos planos e projetos [...]" (LIBÂNEO, 2013, p. 125). Sendo assim, o ato de planejar é abarcado permanentemente por ação e reflexão. Tais elementos serão foco das discussões construídas a partir das narrativas docentes, na sequência do texto.

\subsection{As vozes que embasaram a nossa investigação: uma análise sobre as narrativas docentes}

Em se tratando da escola inclusiva, segundo Carvalho (2013), falar de organização escolar implica falar em planejamento articulado entre gestão, professores e educação especial, repensando a cultura escolar produzida, que deve estar sempre em movimento, e adotando "[...] metodologias de trabalho compartilhado, abandonando-se as tradicionais formas de planejamento em que este é, predominantemente, fruto dos trabalhos de técnicos isolados e encerrados em seus gabinetes, em nível central” (p. 100). Assim, as ações planejadas devem estar ancoradas nas necessidades identificadas em prol do coletivo.

Em sua narrativa, a professora Francisca afirma que não é uma escola pequena ou grande que vai definir a qualidade da organização das práticas, mas ressalta que, especificamente na escola em que atua, por esta ter uma estrutura física e pedagógica bem organizada e contar com um grupo que trabalha de forma colaborativa via diálogo, é possível visualizar a mobilização coletiva para a efetivação das políticas inclusivas.

[...] nessa escola em que a gente está falando hoje, [...] em termos de organização, ela é mais fácil de contemplar as necessidades. Nem sempre isso quer dizer, fique claro, assim, que não é uma escola pequena ou uma escola grande que vai determinar um processo de inclusão com mais significado. Não é isso, mas em termos de organização se torna mais fácil. Por quê? Porque temos menos alunos, é uma escola mais compacta, digamos, que tem uma estrutura relativamente boa. A gente tem um espaço para dar conta do AEE 


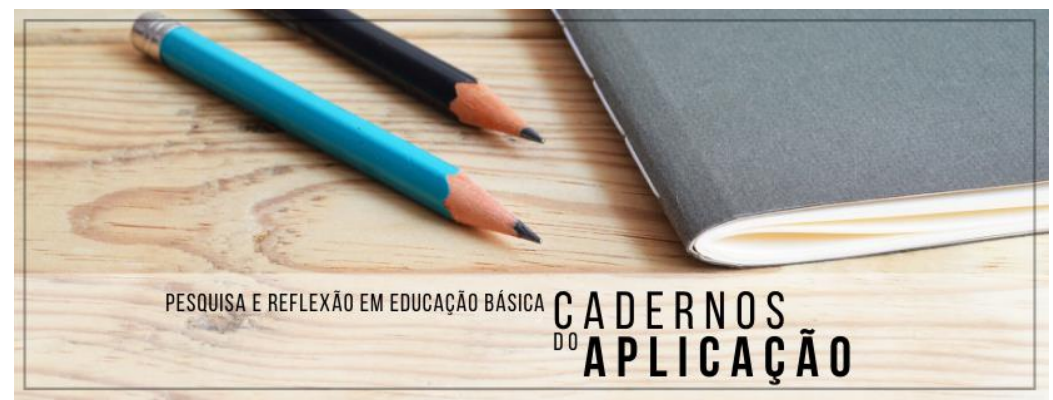

Cadernos do Aplicação

https://seer.ufrgs.br/CadernosdoAplicacao

Publicação Ahead of Print

ISSN 2595-4377 (online)

Porto Alegre | jul-dez. 2021 | v.34 | n.2

que está bem organizado, bem equipado. A gente tem apoio da coordenação pedagógica, da equipe gestora. É um grupo de professores menor também, então, fica mais fácil esse contato, esse vínculo, da conversa do professor do AEE com o professor da classe comum. [...] uma escola grande já envolve um movimento muito maior. Isso não quer dizer que a gente também não tenha que dar conta [...] da resistência, do questionamento, se é válido aquele aluno estar ali, o que fazer com esse aluno, de que forma vai avaliar, de que forma vai colocar as atividades, [...] como qualquer outra escola. (Prof. Francisca).

A partir da organização da escola, a professora Francisca defende a importância de olhar para a sala de aula e considerar que cada estudante, com ou sem diagnóstico ${ }^{7}$, tem o seu tempo e diferentes maneiras para aprender e desenvolver-se. Carvalho (2013) alerta que o diagnóstico é uma das mais sérias barreiras que vêm sendo enfrentada na educação inclusiva, pois a escola ainda acha importante encontrar diagnósticos que justifiquem comportamentos e formas de estar na escola consideradas desviantes, mesmo defendendo o pressuposto de que esse lugar é para todos.

[...] quando tu percebes que nem todas as crianças aprendem do mesmo jeito, [...] o professor que questiona o fato de uma criança com deficiência que não tem a mesma aprendizagem que ela gostaria que ele tivesse, ou que a maioria das crianças estão apresentando, em termos de desempenho, quando coloca assim, eu sempre devolvo a pergunta: "e quantos outros mais?". Porque tem muitas situações numa turma, muitas, e tem alunos que não têm deficiência e que também têm outro ritmo de aprendizagem, só que ele não é visto. Por quê? Porque não está posto que ele tenha uma deficiência. Então, essas questões, a gente ainda tem que trabalhar muito, mas eu acho [...] que alguns professores estão se dando conta também de que aquele aluno pode aprender várias outras coisas, e não só a aprendizagem formal, dentro daquele tempo [...] os próprios alunos vão acabar mostrando para esses profissionais o quanto a aprendizagem é diversa [...] (Prof. Francisca).

É com base nesse olhar atento às múltiplas singularidades que constituem um contexto escolar que nesta discussão nos embrenhamos nas práticas pedagógicas, procurando, a partir das concepções de educação inclusiva, compreender como e por que as professoras planejam suas aulas, organizam as atividades para o grupo de crianças, adaptam e/ou reinventam o currículo.

\footnotetext{
${ }^{7}$ Considera-se diagnóstico o produto de avaliação clínica que indica a presença de uma deficiência, uma síndrome, transtorno ou outra condição presente no sujeito.
} 


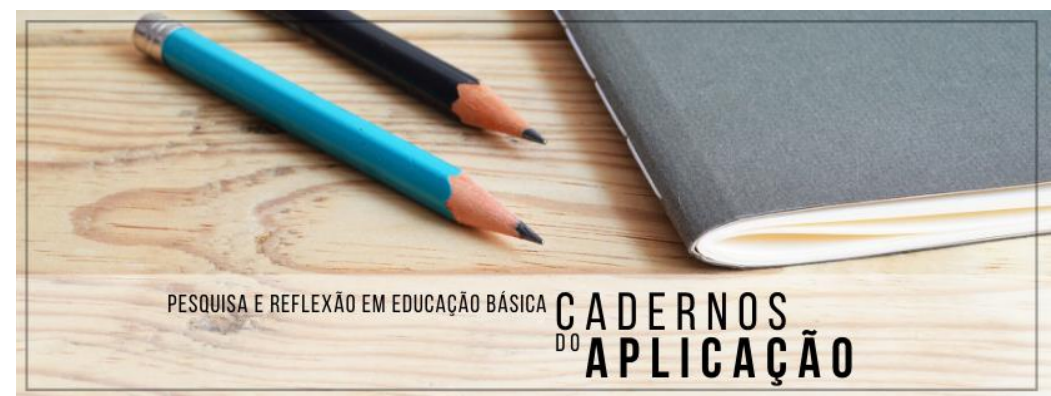

Cadernos do Aplicação

https://seer.ufrgs.br/CadernosdoAplicacao

Publicação Ahead of Print

ISSN 2595-4377 (online)

Porto Alegre | jul-dez. 2021 | v.34 | n.2

Ao planejar em um contexto de educação inclusiva, é temeroso cair no argumento dos conteúdos, no sentido de predizer o que os estudantes podem ou não podem, conseguem ou não conseguem aprender, depauperando o processo de ensino e aprendizagem. Acreditamos que o diagnóstico é um dos motes que influenciam nessa garimpagem. Por isso, podemos considerar que "a manutenção de velhos modelos mediante novas políticas pode significar uma minimização das aprendizagens propostas para grande parte dos alunos, na direção de um empobrecimento dos conteúdos a serem trabalhados [...]" (MICHELS et al., 2010, p. 6). Nesse sentido, podemos perceber, nas narrativas, três caminhos que são percorridos pelas professoras.

A professora Cecília nos faz entender que o seu olhar é abrangente; ela caminha junto com o grupo de crianças e ao mesmo tempo com a aluna em processo de inclusão em um só planejamento, respeitando os limites, intervindo e mediando potencialidades. Em meio ao grupo de crianças, há um cuidado ao propor atividades, mas entendemos que, ao mesmo tempo em que a preocupação é com o todo, há um olhar específico para a criança. Observamos isso na narrativa que segue:

[...] ficar exigindo que ela aprenda o conteúdo específico do plano de estudo é algo ilusório, então, eu preciso, sim, ter esse olhar individualizado, de perceber [...] olhar para esse processo de uma forma diferenciada [...], aí eu não vou olhar [...] para aquilo que a criança aprendeu ou não do conteúdo, eu vou olhar para [...] o que ela conseguiu avançar [...] diversificar em relação às atividades para dar conta dessa aprendizagem específica. [...] eu vejo potencial de aprendizagem dessa criança, as possibilidades que ela tem de acompanhar o ritmo da turma, claro, com algumas reorganizações, algumas coisas que precisam ser diferentes para ela, mas eu procuro inseri-la em todas as atividades. Ela acompanha as atividades junto com os colegas, então, em atividades em grupo, atividades que são mais coletivas, ela participa junto com os colegas; agora, em atividades mais específicas [...], eu vou exigir e vou desafiá-la de acordo com aquilo que ela pode corresponder. Então, em uma produção escrita, eu não vou exigir dela que ela produza o mesmo que os colegas que estão alfabéticos e que estão num nível mais avançado vão produzir. Então, eu vou desenvolver com ela dentro da capacidade que ela tem, se ela escreve silábico, escreve silábico-alfabético, vai ser nessa perspectiva que eu vou olhar: "o que ela conseguiu produzir? O que ela conseguiu avançar? ". [...] eu vou trabalhar com ela e olhar para esse processo para ver o que ela consegue avançar além disso, [...]. E assim eu vou fazendo algumas adaptações, algumas reorganizações das atividades; a atividade pode ser a mesma, o registro, a folhinha, o material pode ser o mesmo. A minha exigência, a minha intervenção para ela vai ser diferente. Então, eu vou organizar de acordo com aquilo que ela pode, [...] para ela, vai ter uma orientação diferente, [...], assim como outras crianças que têm dificuldades 


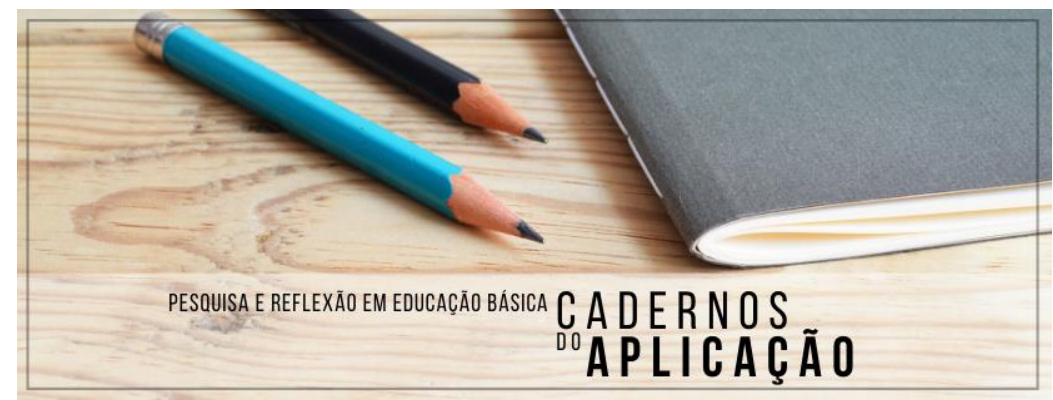

Cadernos do Aplicação

https://seer.ufrgs.br/CadernosdoAplicacao

Publicação Ahead of Print

ISSN 2595-4377 (online)

Porto Alegre | jul-dez. 2021 | v.34 | n.2

específicas em sala de aula [...]. Até mesmo na organização dos agrupamentos, eu procuro colocá-la com alguém que eu sei que vai ter um olhar sensível para ela, então, tem crianças... A Alice ${ }^{8}$, por exemplo, ontem ela sentou com a Alice, a Alice tem paciência para ajudá-la a copiar do quadro. (Prof. Cecília).

Por outro caminho, a professora Antônia traz a ideia de dois planejamentos, um para a turma e outra organização de atividades para o seu aluno em processo de inclusão. Ela também relata que sente que a sua formação inicial em História resultou em uma fragilização relativa às questões didáticas e pedagógicas; por isso, ela busca aprender com a própria experiência e com as pesquisas e leituras que vão surgindo.

[...] Se é um conteúdo que nós estávamos trabalhando, comprimento, unidade de medida, o Enzo ${ }^{9}$ recebe a folha, vai colado no caderno dele, mais para a família saber, [...] nós construímos o metro, o Enzo construiu o metro dele, mediu o tamanho da mesa, o tamanho do caderno. Essa parte prática, ele faz, mas ele não registrou nada, [...] se tu perguntares as coisas pra ele, ele te responde, se perguntares: "Quanto deu teu caderno de altura Enzo?" ele te responde: "tantos centímetros" [...]. Mas que é complicado, é; tu tens que fazer dois planejamentos. [...] quando eu vou trabalhar com o grupo, eu até questiono e ele responde, mas, na hora da escrita e do registro, ele não consegue fazer, aí o registro dele é diferente. Eu vou trabalhar com ele outros exercícios [...] por exemplo, [...] eu estava trabalhando o quilo, eu trouxe uma balancinha para a sala de aula, [...] o Enzo Pesou, mas não registrou nada. Depois, fomos para a folha, cada um fazer o seu registro, anotou o que tinha pesado, quantas gramas, quantos quilos. Eu fui no caderno do Enzo e escrevi BALANÇA, circulei a primeira sílaba e pedi que ele escrevesse uma lista de palavras que começa com BA [...]. Então, procuro associar, assim, mas tem que fazer diferenciado. [...] eu até não tenho nem Pedagogia, eu tenho Magistério, eu tenho curso de História, mas eu tenho muitos anos de experiência, então, eu vou pela minha experiência, eu vou pelo que eu sei. [...] então, assim, tu vais testando, vais vendo o que que dá, [...] vou me virando. (Prof. Antônia).

A professora Renata não faz dois planejamentos; ela procura respeitar os limites e potencialidades da sua aluna dentro das mesmas atividades das demais crianças. Demonstra uma preocupação com os conteúdos que precisam ser trabalhados e constrói uma "meta" para o ano com as habilidades e conteúdos que ela considera importantes para que sua aluna desenvolva e aprenda.

\footnotetext{
${ }^{8}$ Aluna identificada com pseudônimo.

${ }^{9}$ Aluno identificado com pseudônimo.
} 


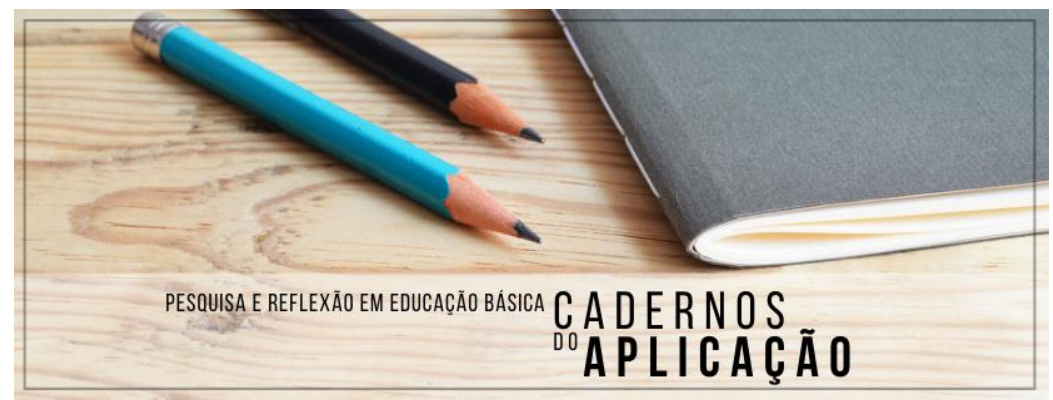

Cadernos do Aplicação

https://seer.ufrgs.br/CadernosdoAplicacao

Publicação Ahead of Print

ISSN 2595-4377 (online)

Porto Alegre | jul-dez. 2021 | v.34 | n.2

Eu dou a mesma sequência com ela que eu dou com os outros, só que com ela o olhar é um pouco diferente, eu dou um olhar conforme eu sei o que ela sabe fazer. Eu sei que ela é desorganizada, que ela tem a letra feia, que ela, às vezes, não se concentra, mas ao mesmo tempo eu tenho que ter aquele olhar do aluno normal com ela, entre aspas normal, porque a gente tem uma bagagem de conteúdos que tem que ser trabalhada, [...] eu tenho um trato assim com as gurias, de buscar com que ela faça o quê? Que ela consiga ler e interpretar um texto, produzir um texto e fazer as quatro operações, essa é a minha meta com ela este ano. [...] Então, são coisas mais básicas com ela. Não exijo que ela saiba, por exemplo, a definição de fotossíntese ou as capitais dos estados do Brasil, mas ela tem o mesmo conteúdo, só eu procuro não cobrar tanto dela [...]. Na mesma base, os exercícios, eu vejo até onde ela consegue ir, porque a prova é igual para todos. Até acho injusto ser diferente para eles. Eu acho que, se eles têm capacidade, têm que ir vendo até onde eles podem ir indo, e eu vou levando até onde ela consegue, exijo o máximo que ela tem capacidade de dar. [...] eu respeito o limite dela, mas tem o mesmo conteúdo dos outros, mesmo planejamento. [...] só ela precisa desses reforços, um reforço do Mais Educação, um reforço de vir com ela, precisa de uma atenção a mais. (Prof. Renata).

A partir dos estudos de Michels et al., (2010), percebe-se que a "[...] diversificação de ações e estratégias produz resultados diferentes no que se refere às concepções que sustentam os processos de inclusão escolar e à qualidade dos atendimentos especializados [...]" (p. 10). Para estas autoras, essa diversificação dá-se por um processo de alternância entre a manutenção e a superação do modelo clínico, com a intenção de caminhar para uma perspectiva pedagógica.

Considerando esses tentames de planejamentos, com o intuito de "vencer" e ao mesmo tempo compreender os desafios da inclusão, a professora Francisca fala da importância do dia a dia como uma das fontes para aprender e compreender sobre a inclusão escolar. É no compartilhamento de experiências, dúvidas, angústias, conquistas, no processo de ação, reflexão e ação, que o entendimento sobre "que lugar é esse" prospera e se constitui. Bolzan (2002) também nos ajuda a pensar sobre as práticas pedagógicas:

O conhecimento pedagógico compartilhado é um sistema de ideias com distintos níveis de concretude e articulação, apresentando dimensões dinâmicas de caráter processual. O processo de constituição do conhecimento pedagógico compartilhado implica a reorganização contínua dos saberes pedagógicos teóricos e práticos, a organização das estratégias de ensino, das atividades de estudo e das rotinas de trabalho, onde o novo se elabora a partir do velho, mediante ajustes desse sistema (p. 147). 


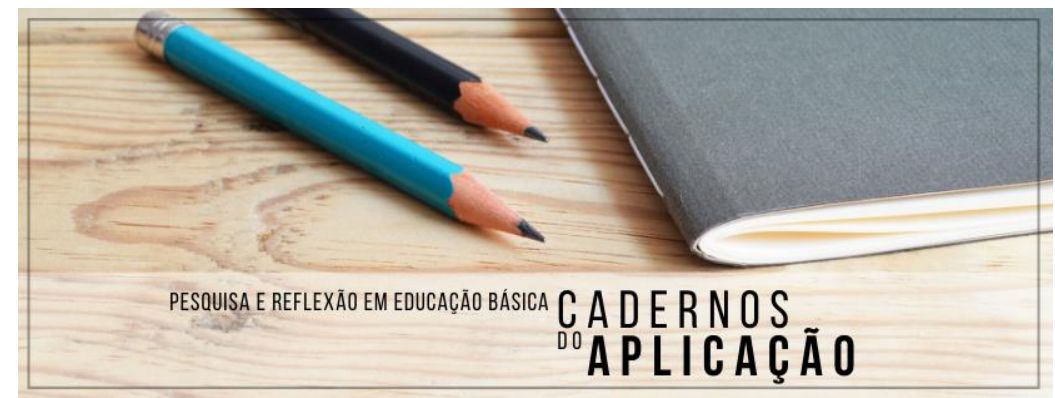

Cadernos do Aplicação

https://seer.ufrgs.br/CadernosdoAplicacao

Publicação Ahead of Print

ISSN 2595-4377 (online)

Porto Alegre | jul-dez. 2021 | v.34 | n.2

Imbricado a esse processo, a professora Francisca ainda chama a atenção para a importância do diálogo entre os profissionais na escola.

[...] Não é falando assim "porque inclusão é isso, deficiência é isso". Isso também é importante, lógico, mas o que vai conseguir mexer, mudar, fazer o processo realmente ter um movimento interessante na escola é esse dia a dia [...] no momento em que tu tens oportunidade de esclarecer algumas coisas, de trocar uma angústia, uma dúvida, que tu estás aberta para isso, e eu sinto os professores daqui abertos para isso [...]. Eu acho que a postura do profissional do AEE também tem que ser flexível para entender as necessidades daqueles professores também que não tiveram essa formação, que, às vezes, não sabem como lidar, que ainda têm uma visão mais antiga do que significa uma pessoa com deficiência, são rótulos que ficaram na sociedade pela história mesmo. Então, desmistificar essas questões de que a criança com deficiência é diferente uma da outra, tem o desenvolvimento diferente, tem uma família diferente, que não é tudo igual. (Prof. Francisca).

A partir dessas narrativas, entendemos haver uma ênfase para o dia a dia escolar como fonte para o reinventar-se professor que precisa planejar na/para a educação inclusiva. Segundo as colocações de Carvalho (2013), "o dia a dia da sala de aula, desde que submetido a uma avaliação crítica e compartilhada, pode ser mais útil ao professor do que um conjunto de livros ou de apontamentos [...]” (p. 161). Nessa lógica, segue ainda a autora, é necessário valorizar e garantir "espaços" de discussões, incluindo-os nas escolas como uma atividade central no planejamento.

Trazemos o diálogo entre as professoras como uma rede com força de mediar tanto as práticas quanto a compreensão do que é desenvolver um trabalho pedagógico na perspectiva da educação inclusiva. Nas narrativas, observamos que há ainda obstáculos relativos ao diálogo entre professoras e a professora da educação especial, mas entendemos que ele existe quando todos conseguem conversar para, juntos, buscarem ações significativas para as pessoas, para o lugar.

Sim, conseguimos muito isso, isso diariamente. [...] em função também de a gente conseguir organizar o horário do profissional do AEE em turnos opostos. Então, tu consegues também ter esse vínculo com o professor de anos iniciais e com os professores de anos finais. (Prof. Francisca).

A professora Francisca diz que, em função da organização do seu horário na escola, ela e as professoras conseguem manter um vínculo mais próximo. Porém, a professora Cecília sente 


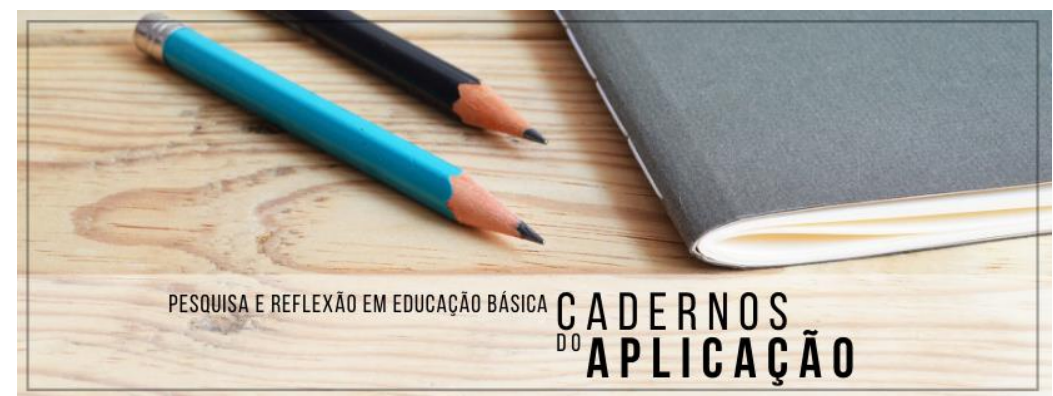

Cadernos do Aplicação

https://seer.ufrgs.br/CadernosdoAplicacao

Publicação Ahead of Print

ISSN 2595-4377 (online)

Porto Alegre | jul-dez. 2021 | v.34 | n.2

falta de mais tempo, pois elas se encontram nos intervalos e as reuniões pedagógicas não dão conta da demanda de assuntos a serem tratados; assim, não conseguem dialogar sobre situações específicas da sala de aula.

Isso é algo complicado, assim... Até pela organização escolar, a gente não tem um tempo para sentar. [...] pelas demandas dela, pelo meu tempo, que é totalmente dedicado para as crianças, e isso acaba se perdendo. Isso eu vejo que é algo que prejudica o trabalho porque não tem esse momento para a gente sentar e pensar sobre as atividades. O nosso momento de conversa é assim, quando ela participa ali do nosso intervalo, a gente conversa, mas eu também, é um momento em que é para ela descansar, para ter aquele intervalo ali, e são essas situações, ou é lá no início da aula, que a gente senta um pouquinho ali junto e eu pergunto alguma coisa, mas o nosso tempo é bem restrito [...]. E são só dois dias na escola [...]. [...] a própria reunião pedagógica é uma vez no mês, e aí tem n coisas que a gente precisa conversar e decidir, e acaba não tendo esse tempo em específico para pensar sobre os casos, até porque são poucos casos na escola [...]. (Prof. Cecília).

As professoras Antônia e Renata fazem-nos entender que, na medida do possível, equilibrando os "minutos" nos intervalos ou em alguma ocasião na escola, elas conseguem conversar, mas não é uma conversa com espaço, tempo e pauta planejada.

Sim, com a Francisca ${ }^{10}$, toda terça e quinta que ela está aqui, a gente se reúne e conversa "E aí, o Enzo veio à aula? O que o Enzo fez hoje?". A Ana" [professora de apoio pedagógico em turno inverso] também. A gente conversa rápido na hora do recreio, e, final de trimestre, a Ana faz um parecer diferenciado do Enzo, só pra ter um parecer dele, ela me passa, e eu comparo com o meu. (Prof. Antônia).

[...] na medida do possível, porque a Francisca sempre tem "n" coisas para fazer dos alunos que ela atende de manhã e de tarde, sempre agenda cheia. Eu também. Quando eu chego de tarde, que eu venho só à tarde, eu vou direto para a sala. Aí, eu tenho uma quinta em que eu venho de manhã pra fechar o horário, que é quando eu consigo conversar com ela, a cada 15 dias. (Prof. Renata).

Percebemos que as professoras chamam a atenção para esse espaço e esse tempo destinados ao diálogo, à conversa e ao compartilhamento das experiências. Consideramos que

\footnotetext{
${ }^{10}$ Pseudônimo da professora da educação especial.

${ }^{11}$ Professora identificada com pseudônimo.
} 
o diálogo sobre o dia a dia na escola instigaria as professoras a tentarem mais, o que seria um fortalecedor para o aprender e compreender o trabalho na educação inclusiva. Entendemos que as professoras estão demonstrando disponibilidade para as discussões, porém, é preciso garantir tempo para que o diálogo se estabeleça e produza planejamentos articulados, mas esse tempo, infelizmente, não parece estar previsto na organização e gestão das práticas da escola.

Conforme já anunciamos, quando a escola significa as orientações inclusivas a partir de políticas que, propondo a organização do trabalho da educação especial na escola comum, deixam subjetiva a ideia de organização de práticas paralelas, parece-nos difícil superar a lógica da inclusão escolar como um projeto de alguns professores, que se desafiam à reinvenção, mas não da escola em si, que opta pela manutenção do instituído, e assim permanece propondo práticas homogêneas para os grupos de alunos, não atentando para as singularidades que se manifestam nesses grupos.

\section{Considerações finais: a visualização de um "entre-lugar" diante das políticas inclusivas}

Desde a década final do século XX, vimos no Brasil uma série de documentos legais e orientadores ser publicada, indicando a necessidade de efetivação de nosso sistema educacional pela perspectiva da educação inclusiva. Movimentando a transição de um modelo clínico para um modelo pedagógico da educação especial, passamos a propor práticas de educação especial não mais com o objetivo de substituir as da educação comum, mas com o de colocá-las como parte desta, apoiando, suplementando e complementando as práticas escolares. É a partir do desafio de conciliar a educação especial com a educação comum, que se produz o questionamento sobre como ser professor e como planejar na escola inclusiva; assim, as adaptações curriculares tornam-se o pano de fundo da pesquisa que deu condições para as discussões aqui desenvolvidas.

Durante o processo de investigação, precisamos repensar nossos entendimentos iniciais. Percebemos que discorrer sobre adaptações curriculares não era simplesmente falar sobre elas. Foi necessário compreender com mais especificidade o que se entende por educação especial e educação inclusiva e como as adaptações curriculares são significadas, tanto a partir da política, dos documentos que orientam a educação inclusiva, quanto das narrativas das professoras. 


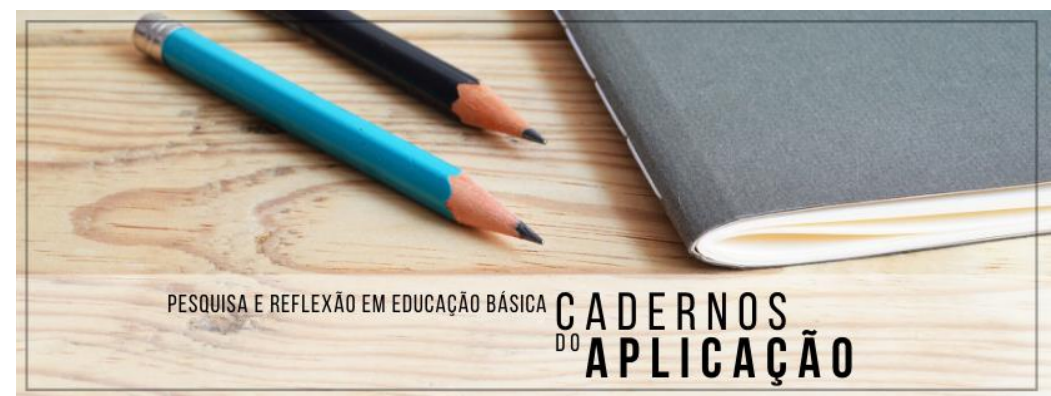

Cadernos do Aplicação

https://seer.ufrgs.br/CadernosdoAplicacao

Publicação Ahead of Print

ISSN 2595-4377 (online)

Porto Alegre | jul-dez. 2021 | v.34 | n.2

Notamos que precisaríamos discutir as práticas pedagógicas que estão sendo pensadas e construídas no contexto da educação inclusiva, e não propriamente falar sobre como algumas práticas vêm sendo adaptadas.

A partir de nosso percurso de pesquisa e das leituras realizadas, entendemos que a forma como as práticas são estruturadas, indicando ou não a realização de adaptações curriculares, pode anunciar as concepções de educação inclusiva construídas pelas professoras. É importante lembrar que, muitas vezes, temos nos preocupado com a implementação de políticas educacionais, não dando atenção ao modo como as escolas têm interpretado, lidado e trabalhado com essas políticas. Ball et al. (2016) apontam que,

[...] enquanto grande atenção tem sido dada para avaliar quão bem as políticas são implementadas, isto é, o quão bem elas são realizadas na prática, menos atenção tem sido dada em compreender e documentar as maneiras pelas quais as escolas realmente lidam com demandas de políticas múltiplas e, às vezes, opacas e contraditórias, e as diversas maneiras que elas criativamente trabalham para fabricar e forjar práticas fora dos textos de política e ideias de políticas em função das suas realidades situadas - um processo de recontextualização que produz algum grau de heterogeneidade na prática ( $\mathrm{p}$. 197-198).

Diante desse contexto de pesquisa, entendemos que, na escola pesquisada, as professoras estão buscando, por diferentes caminhos, uma compreensão sobre a melhor e mais viável forma de implementação das políticas de educação inclusiva. Pensar a educação inclusiva não é uma tarefa simples. Se considerarmos a escola como um espaço constituído por pessoas (professores, alunos, funcionários, famílias) e inclusão como o ato de inserir algumas pessoas em específico nesse grupo já existente, entenderemos a função da escola inclusiva apenas como abertura do espaço físico escolar para aqueles que antes eram dele excluídos. Portanto, assim só estaremos distribuindo "figurantes", sem contribuir com o desenvolvimento desses sujeitos (CARVALHO, 2013). Por isso, sublinhamos a necessidade de reinvenção da escola e de reconfiguração das práticas a partir da concepção de que estas não podem ser propostas para destinatários principais e/ou a priori elegidos.

Mediante as narrativas analisadas, visualizamos duas concepções mais significativas acerca da inclusão escolar: uma que a significa como um dos melhores momentos vividos na educação, e a outra como um desafio que, consequentemente, gera insegurança, mas mobiliza 


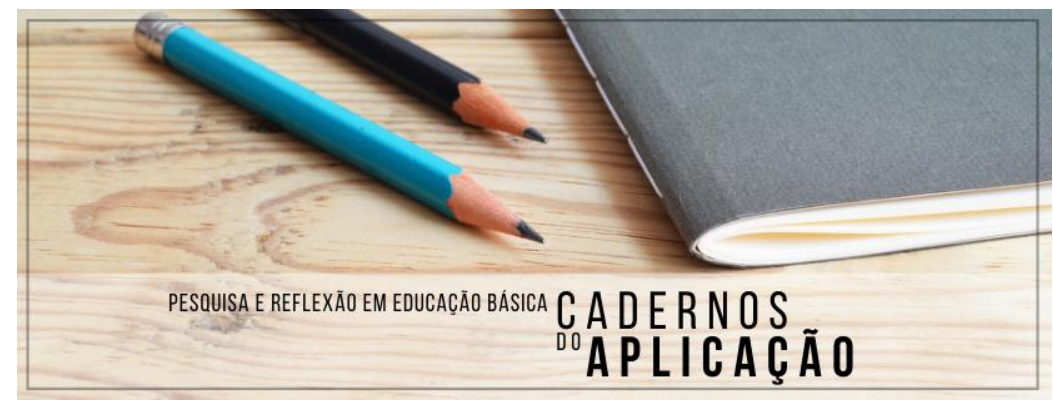

Cadernos do Aplicação https://seer.ufrgs.br/CadernosdoAplicacao

Publicação Ahead of Print

ISSN 2595-4377 (online)

Porto Alegre | jul-dez. 2021 | v.34 | n.2

as professoras para/nas práticas pedagógicas. Essas práticas estão sendo experimentadas a partir de percepções diferentes: um único planejamento para toda a turma, com um olhar cuidadoso para os alunos em processo de inclusão; dois planejamentos, sendo um específico para os alunos em processo de inclusão escolar e um planejamento para toda a turma, contemplando as habilidades e necessidades das crianças com atividades diversificadas com o mesmo objetivo, mas organizadas de diferentes formas.

Entendemos que esse processo de experimentação e reinvenção do fazer docente leva as professoras a fazerem algo mais do que adaptações curriculares. Há uma reflexão sobre suas concepções de escola, os sujeitos que a constituem e as intencionalidades do que para eles é oferecido. Parece-nos que, ao organizarem-se para efetivar práticas pedagógicas consideradas inclusivas, as professoras da escola se mostram preocupadas em compreender o contexto educacional atual, desmistificando ideias produzidas ao longo da história da/na sociedade sobre escola, educação especial, mundo, sociedade, entre outros fatores implicados em seu processo de atuação docente.

Foi possível, então, identificar práticas vinculadas entre ensino regular e educação especial que não se complementam, fazendo-nos compreender que a educação especial se configura como um adendo na escola. E visualizamos, também, práticas articuladas entre educação especial e ensino comum, reorganizadas globalmente para atender às especificidades pedagógicas dos alunos em processo de inclusão escolar. Ao finalizarmos, concluímos que, diante da necessidade de proposição de práticas inclusivas, a escola se organiza em um processo dinâmico, ora buscando sua reinvenção, ora reafirmando o tradicionalmente realizado, processo que nomeamos de um "entre-lugar" - educação inclusiva sendo significada e construída entre o adaptar e o reinventar.

\section{Referências}

ARANHA, Maria Salete Fábio (Org.). Estratégias para a educação de alunos com necessidades educacionais especiais. Brasília: Ministério da Educação, Secretaria de Educação Especial, 2003.

BALL, Stephen J.; MAGUIRE, Meg; BRAUN, Annette. Como as escolas fazem as políticas: atuação em escolas secundárias. Ponta Grossa, PR: Editora UEPG, 2016. 


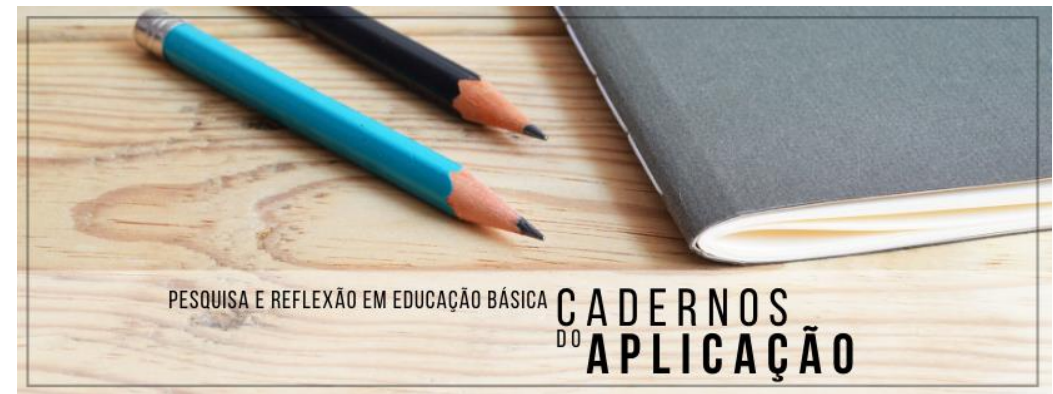

Cadernos do Aplicação https://seer.ufrgs.br/CadernosdoAplicacao

Publicação Ahead of Print

ISSN 2595-4377 (online)

Porto Alegre | jul-dez. 2021 | v.34 | n.2

BEYER, Hugo Otto. O Projeto Político-Pedagógico da Educação Inclusiva e a gestão educacional: reflexões com a área de Educação Especial da Secretaria de Educação do Estado do Rio Grande do Sul. In: FREITAS, Soraia Napoleão (Org.). Tendências Contemporâneas de Inclusão. - Santa Maria: Ed. da UFSM, 2008.

BOLZAN, Dóris Pires Vargas. Formação de professores: compartilhando e reconstruindo conhecimentos. Porto Alegre: Mediação, 2002.

BRASIL. Ministério da Educação. Diretrizes Nacionais para a Educação Especial na Educação Básica. Secretaria de Educação Especial - MEC; SEESP, 2001.

BRASIL. Ministério da Educação. Lei de Diretrizes e Bases da Educação Nacional, LDB 9.394, de 20 de dezembro de 1996. Acesso em 30 de maio de 2021 às 18 h40min. Disponível em <http://portal.mec.gov.br/seesp/arquivos/pdf/lei9394_ldbn1.pdf>

BRASIL. Política Nacional de Educação Especial na perspectiva da Educação Inclusiva. Brasília: MEC/SEESP, 2008.

CARVALHO, Rosita Edler. Educação inclusiva: com os pingos nos “is". - 9. ed. - Porto Alegre: Mediação, 2013.

JOVCHELOVITCH, Sandra; BAUER, Martin. Entrevista Narrativa. In: BAUER, Martin; GASKELL, George. Pesquisa qualitativa com texto, imagem e som: um manual prático. Petrópolis, RJ: Vozes, 2002.

LEITE, Lúcia Pereira; SILVA, Aline Maria. Práticas educativas: adaptações curriculares. In: FIALHO, Vera Lúcia Messias (Org.). Práticas em educação especial e inclusiva na área da deficiência mental. Bauru : MEC/FC/SEE, 2008.

LIBÂNEO, José Carlos. Organização e gestão da escola: teoria e prática. 6. ed. rev. e ampl. São Paulo: Heccus Editora, 2013.

MICHELS, Maria Helena; CARNEIRO, Maria Sylvia Cardoso e GARCIA, Rosalba Maria Cardoso. A articulação entre serviço especializado e classe comum: a organização curricular frente a um modelo inclusivo. Anais da VIII ANPED Sul - FORMAÇÃO, ÉTICA E POLÍTICAS: QUAL PESQUISA? QUAL EDUCAÇÃO? Curitiba: UEL, 2010.

ROSSETO, Gislaine A. R. da Silva; BAPTAGLIN, Leila Adriana; FIGHERA, Adriana Claudia Martins. Narrativas socioculturais: abordagem investigativa para as pesquisas em formação de professores. In: Anais da X ANPED Sul, Florianópolis, 2014.

XAVIER, Maria Luísa M. Educação Básica: o necessário resgate de sua identidade. Cadernos do Aplicação, Porto Alegre, v. 21, n. 2, jul./dez. 2008.

Data de submissão: 15/05/2021

Data de aceite: 07/07/2021

DOI: https://doi.org/10.22456/2595-4377.114304 